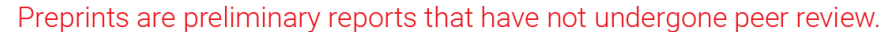 They should not be considered conclusive, used to inform clinical practice, or referenced by the media as validated information. \\ Clinical Risk Factors Associated with Radiographic Osteoarthritis Progression Among People with Knee Pain: A Longitudinal Study
}

\section{Milena Simic}

University of Sydney https://orcid.org/0000-0002-5387-3986

Alison R. Harmer

The University of Sydney

Maria Agaliotis

University of New South Wales

Lillias Nairn

University of Sydney

Lisa Bridgett

University of Sydney

Lyn March

University of Sydney

Milana Votrubec

Notre Dame University

John Edmonds

University of New South Wales

Mark Woodward

The George Institute for Global Health

Richard Day ( $\nabla$ r.day@unsw.edu.au )

St Vincent's Hospital, Darlinghurst https://orcid.org/0000-0002-6045-6937

Marlene Fransen

University of Sydney

\section{Research article}

Keywords: Knee osteoarthritis, disease progression, risk factors, epidemiology, non-steroidal antiinflammatory drugs

Posted Date: September 2nd, 2020

DOI: https://doi.org/10.21203/rs.3.rs-67862/v1 
License: (c) (i) This work is licensed under a Creative Commons Attribution 4.0 International License. Read Full License

Version of Record: A version of this preprint was published at Arthritis Research \& Therapy on June 4th, 2021. See the published version at https://doi.org/10.1186/s13075-021-02540-9. 


\section{Abstract}

\section{Background:}

The aim of this study was to identify modifiable clinical factors associated with radiographic osteoarthritis progression over one-to-two years in people with painful medial knee osteoarthritis.

\section{Methods:}

A longitudinal study was conducted within a randomised controlled trial, the "Long-term Evaluation of Glucosamine Sulfate" (LEGS study). Recruitment occurred 2007-2009, with one and two-year follow-up assessments by blinded assessors. Community-dwelling people with chronic knee pain $(\geq 4 / 10)$ and medial tibiofemoral narrowing (but retaining $>2 \mathrm{~mm}$ medial joint space width) on radiographs were recruited. From 605 participants, follow-up data were available for 498 (82\%, mean[sd] age: 60[8] years). Risk factors evaluated at baseline were pain, physical function, use of non-steroidal anti-inflammatory drugs (NSAIDs), statin use, not meeting physical activity guidelines, presence of Heberden's nodes, history of knee surgery/trauma, and manual occupation. Multivariable logistic regression analysis was conducted adjusting for age, sex, obesity, high blood pressure, allocation to glucosamine and chondroitin treatment, and baseline structural disease severity (Kellgren and Lawrence grade, joint space width and varus alignment). Radiographic osteoarthritis progression was defined as joint space narrowing $\geq 0.5 \mathrm{~mm}$ over one-to-two years (latest follow-up used where available).

\section{Results:}

Radiographic osteoarthritis progression occurred in 58 participants (12\%). Clinical factors independently associated with radiographic progression were: use of NSAIDs, adjusted odds ratios (OR) and $95 \%$ confidence intervals (Cl) 2.05 (95\% Cl:1.1 to 3.8), and not meeting physical activity guidelines, OR 2.07 (95\%Cl:0.9 to 4.7$)$.

\section{Conclusions:}

Among people with mild radiographic knee osteoarthritis, people who use NSAIDs and/or do not meet physical activity guidelines have greater risk of radiographic osteoarthritis progression.

\section{Trial Registration:}

This original study trial was registered apriori. ClinicalTrials.gov identifier: NCT00513422; http://www.clinicaltrials.gov. Current study hypothesis arose before inspection of the data.

\section{Background}

Knee osteoarthritis (OA), which commonly occurs in the medial tibiofemoral compartment ${ }^{1}$, imposes a personal and societal burden ${ }^{2}$. While risk factors for incident knee $\mathrm{OA}$ are well understood ${ }^{3}$, risk factors 
for radiographic OA progression are less known and evidence is frequently conflicting ${ }^{4-6}$. Radiographic OA progression is commonly measured by evaluating tibiofemoral joint space narrowing (JSN) on radiographs. The rate of JSN is strongly correlated to cartilage damage on magnetic resonance imaging $(\mathrm{MRI})^{7}$, to knee pain ${ }^{8}$, and predicts the need for joint replacement surgery ${ }^{9}$. The rate of joint deterioration varies among individuals, with $57 \%$ likely to remain stable, $2 \%$ regress, and $41 \%$ deteriorate over 15 years ${ }^{10}$. Among people who demonstrate joint deterioration, larger changes in JSN predict future OArelated surgery ${ }^{9}$. Therefore, the ability to identify individuals likely to experience radiographic $O A$ progression is needed to more effectively tailor therapy.

Systematic reviews of risk factors for radiographic OA progression ${ }^{5,11}$ identified strong evidence that greater structural disease severity at baseline (such as marked loss of tibiofemoral joint space width and varus alignment) is associated with radiographic knee OA progression risk. However, there are conflicting findings regarding the risks associated with older age, obesity, past knee injury, pain and physical function (activity limitation). Furthermore, it is unknown if people who are physically inactive, using nonsteroidal anti-inflammatory drugs (NSAIDs), or using statins (hypothesised to influence cartilage lipid function), are at greater risk of radiographic OA progression. Previous studies have failed to adjust for known factors, such as baseline structural disease severity, which may explain conflicting findings 6,12 .

\section{Methods}

\section{Aim}

The aim of this study was to identify modifiable clinical factors that are associated with radiographic $O A$ progression in the medial tibiofemoral compartment. Specifically, we aimed to identify if any modifiable clinical factors are independently associated with medial tibiofemoral compartment JSN over one-to-two years in people with symptomatic knee OA, when adjusting for baseline structural disease severity.

\section{Design and study setting}

A longitudinal study was undertaken as part of a double-blind randomised controlled trial (RCT) evaluating the effect of two dietary supplements (glucosamine sulfate $(1500 \mathrm{mg})$ and/or chondroitin sulfate $(800 \mathrm{mg})$ ) on knee OA disease progression over two years: Long-term Evaluation of Glucosamine Sulfate (LEGS) study ${ }^{13}$. People with symptomatic knee OA were recruited from the local community through advertisements and primary care centres in New South Wales, Australia, during 2007-2009. All measures (baseline or follow-up) for an individual were collected on a single day at one of four radiology departments. Follow-up assessments were conducted one and two years later. The study complies with the Declaration of Helsinki. Ethics approval was granted by the Human Research Ethics Committee, University of Sydney (No.8821), and all participants provided written informed consent.

\section{Participants}


Individuals were potentially eligible if they were aged $45-75$ years, had knee pain over the past six months, had pain on most days of the past month and rated "worst" pain over the past week as $\geq 4$ on a 0-10 numeric rating scale. They were excluded if they reported having rheumatoid arthritis, bilateral knee replacements, unstable diabetes, allergy to shellfish, lower limb surgery in the past six months, intraarticular injections in the past three months or planned knee replacement surgery in the next year ${ }^{13}$.

Weight-bearing magnification-controlled posterior-anterior semi-flexed radiographs of both knees were undertaken using a standardised metatarsophalangeal protocol and foot maps ${ }^{14}$. The protocol permitted one repeat, changing the angulation of the beam if the medial tibial inter-rim distance (TIRD) was > $2.0 \mathrm{~mm}^{15}$. Participants were included if a symptomatic knee demonstrated reduced medial tibiofemoral joint space width in comparison with the lateral compartment, but had at least $2.0 \mathrm{~mm}$ of joint width.

\section{Risk factors}

Data were collected on age, sex, symptom duration, Body Mass Index (BMI) and waist circumference. Previous self-reported knee trauma or surgery was recorded. Participants' occupations were classified as manual/physical labour if they reported work in the following areas: technicians/trades, machine operators/drivers, or labourers. Participants were asked to report any regular medication taken during the previous seven days (including self-prescribed over-the-counter medication), and used to identify NSAID and statin use. Adjustment was made for being allocated to the "double active" intervention group (glucosamine sulfate and chondroitin sulfate; $25 \%$ of the cohort) because the results of the RCT demonstrated a reduction in JSN for this allocation compared with placebo ${ }^{13}$.

Self-reported knee pain and physical function (activity limitation) were assessed using the Western Ontario and McMaster Universities (WOMAC) OA Index, a reliable and valid disease-specific questionnaire $^{16}$. The WOMAC index (Likert scale) contains subscales for pain (range 0-20) and physical function (range 0-68) where higher scores indicate worse pain or poorer function.

Leisure time physical activity (LTPA) was self-reported using a standardised valid and reliable national questionnaire from the Australian Institute of Health and Welfare ${ }^{17}$. Participants reported activity intensity, frequency, and duration, which was used to determine if physical activity guidelines were met (five sessions, $>150$ minutes of activity/week) ${ }^{18}$.

Comorbidity was evaluated via the Self-Administered Co-morbidity Questionnaire ${ }^{19}$. The comorbidity questionnaire is scored out of 36 , with points allocated for presence of a condition, treatment and activity limitation.

For descriptive purposes, health-related quality of life was evaluated using the Medical Outcomes Survey Short Form (SF-12v2) questionnaire, from which two norm-referenced scores were extrapolated: the Physical Component Summary Score (PCS) and the Mental Component Summary Score (MCS) ${ }^{20}$, each with a mean (standard deviation (SD)) of 50 (10) in the general population.

\section{Structural disease severity}


Baseline structural disease severity was evaluated using: i) Kellgren and Lawrence (K\&L) OA grading scale $^{21}$; ii) minimum medial joint space width; and iii) tibiofemoral alignment. A single assessor (MF), blinded to treatment but not assessment time-point, measured all radiographs for medial compartment joint space width ${ }^{22}$ using digitized image analysis software (Holy's, UCLB, Lyon, France).

Knee alignment was evaluated by measuring the anatomical tibiofemoral alignment from available radiographs, and used to calculate the mechanical knee alignment (usually measured by full-length radiographs) using a regression Eq. $2^{3}$. Anatomical alignment axis was the knee joint center (midpoint of the tibial spines tips) ${ }^{24}$, and the angle obtained by drawing $10 \mathrm{~cm}$ proximal and distal from the centre towards the midshafts of the femur and tibia, respectively. Values of $180^{\circ}$ signified neutral alignment, > $180^{\circ}$ indicated valgus, and $<180^{\circ}$ indicated varus. A single assessor (MS) conducted all measurements using RadiAnt DICOM Viewer (version 1.9; Medixant, Poland; intra-class correlation coefficient of 20 participants $=0.93, p<0.001)$.

\section{Radiographic OA progression}

Minimum medial joint space width $(\mathrm{mm})$ was evaluated at all assessment time-points. Only radiographs with TIRD of $<1.7 \mathrm{~mm}$ at each time-point and $\leq 0.2 \mathrm{~mm}$ difference in TIRD between radiographic evaluations at two time-points (baseline, year one or two) were eligible for longitudinal analyses. The primary outcome was medial tibiofemoral JSN $\geq 0.5 \mathrm{~mm}$. The $0.5 \mathrm{~mm}$ reduction in JSN is the recommended cut-off value according to the OARSI-OMERACT recommendations, as JSN $\geq 0.5 \mathrm{~mm}$ over two years is considered to indicate high risk for joint replacement surgery ${ }^{25}$ and is a reliable indicator of disease progression ${ }^{26}$. If a follow-up radiograph was unavailable at two years, the radiograph at one year was used to determine if $\mathrm{JSN}$ was $\geq 0.5 \mathrm{~mm}$.

\section{Statistical analysis}

Descriptive statistics such as mean (SD) or number (\%) were presented and analyses conducted using SPSS (v22). Potential clinical risk factors which were significantly correlated $(r>0.5 ; p<0.05)$ were combined into a single factor if they measured a common construct. Of the factors, high BMI $(\geq$ $30 \mathrm{~kg} / \mathrm{m}^{2}$ ) and waist circumference (>102 cm for men, $>88 \mathrm{~cm}$ for women) were significantly correlated and therefore evaluated as a single obesity risk factor (participants considered obese if at least one factor was present).

All baseline clinical risk factors were dichotomized for subsequent analyses. The following factors were investigated: aged $>60$ years, female sex, obesity (BMI $\geq 30 \mathrm{~kg} / \mathrm{m}^{2}$, or high waist circumference), high blood pressure, presence of Heberden nodes, history of knee surgery/trauma, history of main occupation involving manual/physical labor, use of NSAIDs, use of statins (HMG-CoA reductase inhibitors used for lowering cholesterol), not allocated to "double active" treatment (no treatment of daily combined glucosamine sulfate $(1500 \mathrm{mg})$ and chondroitin sulfate $(800 \mathrm{mg})$ ), high pain at baseline (worst $20 \%$ of the cohort on WOMAC $(>10 / 20)$ ), poor physical function (worst $20 \%$ of the cohort on WOMAC $(>33 / 68)$ ), 
and not meeting physical activity guidelines ( $<150$ minutes of moderate-to-vigorous physical activity/week).

The following structural disease severity factors were investigated and included in all models: moderateto-severe $O A(K \& L \geq 2)$, minimal baseline medial joint space width (the lowest $20 \%$ within the cohort, $2.00 \mathrm{~mm}-3.13 \mathrm{~mm})$, and varus alignment $\left(\leq 178^{\circ}\right)$.

Due to the potential for some known risk factors to be associated with radiographic OA progression, the following variables were chosen a priori to be included as fixed variables in the multivariable model, thus adjusting for: age, sex, obesity, high blood pressure ${ }^{27}$, high pain at baseline, no glucosamine/chondroitin "double active" treatment, and baseline structural disease severity factors. Univariate associations were examined for all potential clinical risk factors at baseline. Clinical risk factors potentially associated with radiographic OA progression $(p<0.2)$ were then ranked by Pearson $\chi^{2}$ values from highest to lowest to determine order of presentation to a multivariable binary logistic stepwise regression analysis. Variables were retained in the multivariable model if they did not affect model stability (change in standard error of variables $<20 \%$ ) and their $p$-value was $<0.1^{28}$. Odds ratios $(\mathrm{OR})$ and $95 \%$ confidence intervals $(95 \% \mathrm{Cl})$ were calculated for each factor associated with radiographic OA progression. Any confirmed clinical risk factor(s) from the multivariable model was then used in exploratory post-hoc univariate analyses with all other univariate variables using the $\chi^{2}$ test. If medication use was a confirmed risk factor, post-hoc analyses were attempted to determine the medication type.

\section{Results}

\section{Flow of participants}

From the 605 participants randomised in the LEGS study, 521 participants attended the radiographic assessment at one year, and 484 participants attended the two-year radiographic assessment. Follow-up radiographs meeting the specifications for assessment (TIRD of $<1.7 \mathrm{~mm}$ at each time-point and $\leq$ $0.2 \mathrm{~mm}$ difference in TIRD between radiographic evaluations) were available for 369 participants (61\%) at two years, and for an additional 129 participants $(21 \%)$ at one year for whom the two year radiographs were not available or of inadequate standard for joint space measurement. Therefore, our analysis was conducted on 498 participants ( $82 \%$ of the sample) who had knee radiographs eligible for longitudinal analysis. There were no differences in baseline characteristics between all participants recruited and those completing follow-up.

Overall, $51 \%$ of participants were obese (Table 1), and the mean quality of life scores (particularly PCS) were below the Australian population norms for ages $45-75$ years $^{29}$. The low comorbidity score indicates a reasonably healthy sample. Most common comorbidities were back pain (38\%), high blood pressure (33\%), depression (16\%), heart disease (11\%), and diabetes (6\%).

\section{Factors associated with radiographic OA progression}


Radiographic OA progression occurred in 58 participants (12\%), of which 47 were evaluated at year two and 11 at one year. In the univariate analysis, clinical factors which met the criteria for inclusion into the multivariable model were NSAID use, inadequate physical activity, and high baseline pain (Table 2). All indicators of structural disease severity were associated with OA progression $(p<0.001)$.

After adjusting for age, gender, obesity, high blood pressure, no glucosamine/chondroitin supplements, and structural disease severity, people who used NSAIDs at baseline (OR 2.05, 95\%Cl:1.10-3.84) and people who did not meet physical activity guidelines (OR 2.07, 95\% Cl:0.92-4.68) were associated with greater odds of radiographic OA progression (Table 3). High baseline pain was no longer significant, but remained in the model as a covariate to adjust for pain. The model explained $16 \%$ of the variance in JSN $\geq 0.5 \mathrm{~mm}$ over one-to-two years. Structural disease severity was associated with significantly higher odds of $\mathrm{JSN} \geq 0.5 \mathrm{~mm}$, including minimal medial joint space width at baseline (OR 2.53, 95\% Cl:1.31-4.88), varus alignment (OR 2.23, 95\%Cl:1.09-4.57), K\&L grade $\geq 2$ at baseline (OR 1.88, 95\%Cl:0.98-3.58). The proportion of participants with radiographic OA progression, based on the number of risk factors, is illustrated in Fig. 1.

Among participants who used NSAIDs (Table 1), the most predominant were aspirin (35\%), meloxicam (24\%), ibuprofen (16\%), and diclofenac (12\%). Due to small numbers, post-hoc analyses for each class of NSAIDs used by participants could not be conducted, however analysis of NSAIDs use without aspirin was performed and yielded similar results. After adjusting for the same factors (age, gender, obesity, high blood pressure, no glucosamine/chondroitin supplements, and structural disease severity), people who used NSAIDs (all except for aspirin) at baseline were associated with greater odds of radiographic OA progression (OR 2.27, 95\% Cl:1.15-4.46).

Exploratory post-hoc $\chi^{2}$ tests (Appendix 1 ) identified that at baseline, a larger proportion of NSAID users in comparison with non-NSAID users had high pain ( $34 \%$ vs $18 \%, p<0.001)$, poor physical function ( $31 \%$ vs $18 \%, p=0.003)$, and greater reported use of statins ( $33 \%$ vs $24 \%, p=0.038$ ). A larger proportion of people who did not meet physical activity guidelines, in comparison with those who did, were not allocated to "double active" glucosamine/chondroitin group ( $77 \%$ vs $65 \%, p=0.012)$.

\section{Discussion}

Radiographic OA progression over one-to-two years occurred in 58 (12\%) participants. Results of this longitudinal study show that people who used NSAIDs and those who did not meet physical activity guidelines independently had double the odds of radiographic knee OA progression compared to people who did not. The study also confirms that people with more severe structural disease at baseline have greater odds of radiographic OA progression. These findings have implications for understanding the pathogenesis of medial knee $\mathrm{OA}$ and provide guidance regarding potential interventions for secondary prevention. 
Clinical guidelines recommend use of NSAIDs for people with chronic knee pain unrelieved by simple analgesics ${ }^{30,31}$. International guidelines also state that NSAIDs should not be recommended for long-term use due to gastrointestinal and cardiovascular adverse effects ${ }^{32,33}$. While causality cannot be confirmed with this longitudinal cohort study, there may be several reasons why we identified a two-fold increased odds of radiographic OA progression among people who reported NSAID use at baseline. Potential mechanisms of elevated progression risk may be due to a physiological effect of the drugs, the representation of people with more severe symptoms, or a representation of people more likely to be physically active due to pharmacological treatment (if activity was proven detrimental to OA). Post-hoc analysis provides some support that NSAID users may represent people with greater symptoms, and thus more severe disease. However, this theory is unlikely to fully explain the findings because high baseline pain was not associated with radiographic $O A$ progression in the multivariable analysis. There is also evidence of a potential physiological effect of NSAIDs. Other longitudinal observational and RCTs studies have identified an increased risk of OA progression in people who use NSAIDs, and this may be dependent on the type of NSAID. A placebo-controlled RCT reported that indomethacin use increased progression over a one-year period, compared with placebo, while tiaprofenic acid did not ${ }^{34}$. Similarly, a longitudinal cohort study of 2,330 people with hip or knee OA examined risk of radiographic OA progression with four common NSAIDs over a mean 7-year follow-up ${ }^{35}$. People who used diclofenac had 2.5-fold increased odds of knee OA progression if diclofenac was taken for 31-180 days, and 3.2-fold increased odds if diclofenac was taken $>180$ days; whereas ibuprofen, naproxen and piroxicam were not associated with increased progression. Conversely, cohort data from the Osteoarthritis Initiative (OAI) did not support an increased risk with NSAIDs among their sample of 2,890 participants ${ }^{36}$. There may also be support for protective effects of some NSAID classes in other longitudinal studies, with low dose aspirin use associated with less medial tibial cartilage loss over two years compared to non-aspirin users $^{37}$. The high proportion of aspirin use in our study was likely for cardiovascular prophylaxis given the sample was middle aged, overweight, and had high blood pressure. A systematic evaluation of the clinical measures of disease progression with different NSAIDs is required for a clearer understanding of potential effects.

People who did not meet guidelines for adequate physical activity had double the odds of radiographic OA progression compared to those who met the guidelines. Due to the observational design, we can only speculate about the causes of the risk. These may include the physiological effect of low physical activity, an association with poor general health or comorbidity, or presence of more pain or activity limitations in these individuals. Post-hoc analysis does not provide support for the abovementioned potential hypotheses. Although a slightly greater proportion of participants not meeting physical activity guidelines were allocated to treatment groups other than the "double active" combined supplements group, thus potentially representing less people in the active therapy group which slowed OA progression in the main trial ${ }^{13}$. This theory is unlikely to explain the findings because treatment allocation was not associated with radiographic OA progression in the multivariable analysis. Despite anecdotal suggestions that high physical activity may be detrimental to OA progression via increased cumulative loading ${ }^{38}$, our results suggest that maintaining adequate physical activity is not associated with 
increased risk and may potentially slow OA progression. Despite the lack of statistical significance in previous studies of physical activity, and a $95 \% \mathrm{Cl}$ which crosses 1.0 in our study, the previously reported mean ORs (range: 0.4 to 0.7 ) suggest agreement with our findings and a potential protective effect of physical activity. Previous studies ${ }^{6,12}$ did not specifically evaluate physical activity duration or intensity at baseline, had smaller cohorts and did not consider radiographic factors in their analyses. Our findings for the protective effects of physical activity are also consistent with a systematic review which identified that runners had a $50 \%$ reduced odds of requiring surgery due to their knee OA compared to nonrunners ${ }^{39}$. A mechanism of joint protection is unknown, however the link between inactivity and chronic low-grade inflammation may explain the identified risk ${ }^{40}$. Muscle strength may present another possible explanation, with high levels of physical activity associated with greater quadriceps strength ${ }^{41}$, which is speculated to support the joint with improved shock-absorption and load distribution ${ }^{42}$. However, associations between muscle strength and disease progression are conflicting and require further investigation ${ }^{5,11}$. Studies implementing a physical activity intervention should evaluate effects on joint biology, mediating factors and OA progression.

The strongest risk factors for radiographic OA progression were baseline structural disease severity measures, indicating that once OA is clearly established on $x$-ray, OA progression is likely. Our findings are consistent with previous studies which identified similar strengths of association (mean OR range: 1.74.5) ${ }^{11}$. Varus alignment is also a known factor associated with radiographic knee OA progression, with the current study identifying a two-fold increase in odds. This is in agreement with published studies (reported ORs range: $2.3-11.0)^{11}$. The variability in the magnitude of ORs is likely due to different criteria used to measure progression, the angle of varus alignment and the covariates in the statistical model.

We did not find an association between daily combined glucosamine and chondroitin supplements and the OARSI-OMERACT recommended target for defining disease progression (JSN $\geq 0.5 \mathrm{~mm}$ over two years). While no effect was identified for rapid progression, the original study confirmed that participants taking the combination supplement experienced a mean of $0.1 \mathrm{~mm}$ less JSN in comparison to the placebo group over two years ${ }^{13}$. This is in agreement with a longitudinal analysis involving the OAI cohort $^{43}$, which identified a disease modifying effect of glucosamine and chondroitin sulfate among people with early OA but not among people with more severe OA. While this benefit has not been shown among people with moderate-to-severe disease ${ }^{44}$, the small disease-modifying effect of combined glucosamine and chondroitin during early stages of OA may potentially delay the requirement for joint replacement surgery.

Risk of radiographic OA progression will be higher for people with multiple risk factors. As demonstrated in Fig. 1, $5 \%$ of people with only one risk factor demonstrated radiographic OA progression, whereas $36 \%$ of people with four or more factors demonstrated progression. Clinicians should routinely assess known risk factors to identify people at greatest risk of progression and potential need for joint replacement surgery. Lastly, we did not find an association with age, sex, or obesity, consistent with findings from a systematic review evaluating risk factors of radiographic $0 A$ progression ${ }^{11}$. 
Strengths of this study include the prospective design, consideration of baseline structural disease severity, evaluation of clinically-relevant modifiable factors, and participants with predominantly mild radiographic $\mathrm{OA}$ at baseline. We also employed a standardised radiographic protocol for image acquisition and evaluation by a single researcher. There are some limitations to be considered when interpreting these findings. As recruitment was for an intervention involving supplements, our results apply to people with symptomatic knee OA seeking treatment. Our analysis was based on self-reported regular NSAID use over the seven days prior to baseline assessment, which may not reflect continual use of NSAIDs throughout the study. As the study was not powered to separately evaluate risk of different NSAID classes, future studies should determine if there is a differential effect specific to the class and/or dosage of NSAIDs. However, the significant finding maintained in our post-hoc analysis for NSAIDs with the exclusion of aspirin confirms the presence of increased risk. Our analysis adjusted for nine identified and/or known confounding variables. It is possible that other factors not evaluated may be important to further understand the relationship between NSAID use, physical activity, and radiographic OA progression. With observational longitudinal study designs of radiographic disease progression, there is a possibility of collider bias ${ }^{45}$. As only participants with pre-existing radiographic knee OA were included, conditioning on radiographic OA may bias the effect of risk factors, such as baseline structural disease severity, towards the null effect. Good quality two-year follow-up radiographs were available for $61 \%$ of participants, limiting our ability to detect all people with JSN $\geq 0.5 \mathrm{~mm}$. Finally, as this was an observational longitudinal study, risk factors imply an increase in the odds of disease progression, and causality needs to be confirmed using RCT designs.

Meeting physical activity guidelines should be encouraged among people with symptomatic knee OA with mild structural disease severity, as this may be protective in the risk of radiographic OA progression over one-to-two years. Clinicians, and people with knee OA, need to be aware of the increased risk of progression among people who use NSAIDs. The strongest associations with radiographic progression were features of disease severity. Interventions targeting prevention of radiographic OA progression are likely to be most effective during the early stage of knee $\mathrm{OA}$, when only mild features are evident on radiographs.

\section{List Of Abbreviations}

BMI Body Mass Index

JSN joint space narrowing

K\&L Kellgren and Lawrence OA grading scale

LEGS Long-term Evaluation of Glucosamine Sulfate study

LTPA Leisure time physical activity

MCS Mental Component Summary Score 
MRI magnetic resonance imaging

NSAIDs non-steroidal anti-inflammatory drugs

OA Osteoarthritis

OR Odds Ratio

PCS Physical Component Summary Score

$\mathrm{RCT}$ randomised controlled trial

SD Standard Deviation

SF-12v2 Medical Outcomes Survey Short Form

TIRD medial tibial inter-rim distance

WOMAC Western Ontario and McMaster Universities (WOMAC) OA Index

95\% Cl 95\% Confidence Interval

\section{Declarations}

\section{Ethics approval:}

The University of Sydney Human Research Ethics Committee approved this study (No.8821). All participants gave written informed consent before data collection began.

\section{Consent for publication:}

This manuscript does not contant any individual person's data in any form.

\section{Availability of data and materials:}

The datasets used during the current study are available from the corresponding author on reasonable request.

\section{Competing interests:}

No competing interests identified with any authors.

\section{Funding:}

This work was supported by the National Health and Medical Research Council of Australia [ID 402511], Department of Health and Ageing [Australia; ID 402781] and supplementary funding ( $<15 \%$ in total) from 
Sanofi-Aventis Consumer Healthcare Pty Ltd, Australia. MS is supported by the Sydney Research Accelerator (SOAR) fellowship.

\section{Role of funding sources:}

The funders had no role in the design or conduct of the study; collection, management, analysis, or interpretation of the data; or preparation, review, or approval of the manuscript.

\section{Author contributions:}

every author listed met the ICMJE criteria for authorship. Conception and study design: MS, MF, AH, JE, MW, RD. Acquisition of data: MS, MF, MA, LN, LS, MV. Analysis and interpretation: MS, MF, AH, LM, RD; Drafting of article: MS, MF, AH. Critical revision of article for important intellectual content: LM, JE, MW, RC, MV, MA, LN, LB. Final approval of the article: All authors.

Milena Simic (milena.simic@sydney.edu.au) takes responsibility for the integrity of the work as a whole, from inception to finished article.

\section{Acknowledgements:}

We would like to acknowledge the participants who enrolled in the study. We also wish to acknowledge Jenny Peat for her statistical support.

\section{References}

1. Dillon CF, Rasch EK, Gu QP, Hirsch R. Prevalence of knee osteoarthritis in the United States: Arthritis data from the third national health and nutrition examination survey 1991-94. The Journal of Rheumatology 2006; 33(11): 2271-9.

2. Cross M, Smith E, Hoy D, et al. The global burden of hip and knee osteoarthritis: estimates from the Global Burden of Disease 2010 study. Ann Rheum Dis 2014; 73(7): 1323-30.

3. Silverwood V, Blagojevic-Bucknall M, Jinks C, Jordan JL, Protheroe J, Jordan KP. Current evidence on risk factors for knee osteoarthritis in older adults: a systematic review and meta-analysis. Osteoarthritis and Cartilage 2015; 23(4): 507-15.

4. Biswal S, Hastie T, Andriacchi TP, Bergman GA, Dillingham MF, Lang P. Risk factors for progressive cartilage loss in the knee. Arthritis \& Rheumatism 2002; 46(11): 2884-92.

5. Chapple CM, Nicholson H, Baxter GD, Abbott JH. Patient characteristics that predict progression of knee osteoarthritis: A systematic review of prognostic studies. Arthritis Care \& Research 2011; 63(8): 1115-25.

6. Cooper C, Snow S, McAlindon TE, et al. Risk factors for the incidence and progression of radiographic knee osteoarthritis. Arthritis \& Rheumatism 2000; 43(5): 995-1000. 
7. Crema MD, Nevitt MC, Guermazi A, et al. Progression of cartilage damage and meniscal pathology over 30 months is associated with an increase in radiographic tibiofemoral joint space narrowing in persons with knee OA - the MOST study. Osteoarthritis and Cartilage 2014; 22(10): 1743-7.

8. Muraki S, Akune T, En-yo Y, et al. Joint space narrowing, body mass index, and knee pain: the ROAD study. Osteoarthritis and Cartilage 2015; 23(6): 874-81.

9. Bruyere 0 , Richy F, Reginster J-Y. Three year joint space narrowing predicts long term incidence of knee surgery in patients with osteoarthritis: an eight year prospective follow up study. Ann Rheum Dis 2005; 64(12): 1727-30.

10. Leyland KM, Hart DJ, Javaid MK, et al. The natural history of radiographic knee osteoarthritis: A fourteen-year population-based cohort study. Arthritis \& Rheumatism 2012; 64(7): 2243-51.

11. Bastick A, Belo J, Runhaar J, Bierma-Zeinstra SMA. What are the prognostic factors for radiographic progression of knee osteoarthritis? A meta-analysis. Clin Orthop Rel Res 2015; 473(9): 2969-89.

12. Schouten JS, van den Ouweland FA, Valkenburg HA. A 12 year follow up study in the general population on prognostic factors of cartilage loss in osteoarthritis of the knee. Ann Rheum Dis 1992; 51(8): 932-7.

13. Fransen M, Agaliotis M, Nairn L, et al. Glucosamine and chondroitin for knee osteoarthritis: a doubleblind randomised placebo-controlled clinical trial evaluating single and combination regimens. Ann Rheum Dis 2015; 74(5): 851-8.

14. Buckland-Wright JC, Wolfe F, Ward RJ, Flowers N, Hayne C. Substantial superiority of semiflexed (MTP) views in knee osteoarthritis: a comparative radiographic study, without fluoroscopy, of standing extended, semiflexed (MTP), and schuss views. J Rheumatol 1999; 26(12): 2664-74.

15. Conrozier T, Mathieu P, Piperno $M$, et al. Selection of knee radiographs for trials of structuremodifying drugs in patients with knee osteoarthritis: A prospective, longitudinal study of lyon schuss knee radiographs with the definition of adequate alignment of the medial tibial plateau. Arthritis \& Rheumatism 2005; 52(5): 1411-7.

16. Bellamy N, Buchanan WW, Goldsmith CH, Campbell J, Stitt LW. Validation-study of WOMAC - A Health-status instrument for measuring clinically important patient relevant outcomes to antirheumatic drug-therapy in patients with osteo-arthritis of the hip or knee. The Journal of Rheumatology 1988; 15(12): 1833-40.

17. Armstrong T, Bauman A, Davies J. Physical activity patterns of Australian adults. Results of the 1999 National Physical Activity Survey. Canberra: Australian Institute of Health and Welfare; 2000.

18. Garber CE, Blissmer B, Deschenes MR, et al. Quantity and quality of exercise for developing and maintaining cardiorespiratory, musculoskeletal, and neuromotor fitness in apparently healthy adults: Guidance for prescribing exercise. Med Sci Sports Exerc 2011; 43(7): 1334-59.

19. Sangha O, Stucki G, Liang MH, Fossel AH, Katz JN. The self-administered comorbidity questionnaire: A new method to assess comorbidity for clinical and health services research. Arthritis Care \& Research 2003; 49(2): 156-63. 
20. Gandhi SK, Warren Salmon J, Zhao SZ, Lambert BL, Gore PR, Conrad K. Psychometric evaluation of the 12-item short-form health survey (SF-12) in osteoarthritis and rheumatoid arthritis clinical trials. Clinical Therapeutics 2001; 23(7): 1080-98.

21. Kellgren JH, Lawrence JS. Radiological assessment of osteo-arthrosis. Ann Rheum Dis 1957; 16(4): 485-93.

22. Hellio Le Graverand M-P, Vignon EP, Brandt KD, et al. Head-to-head comparison of the Lyon Schuss and fixed flexion radiographic techniques. Long-term reproducibility in normal knees and sensitivity to change in osteoarthritic knees. Ann Rheum Dis 2008; 67(11): 1562-6.

23. Hinman RS, May RL, Crossley KM. Is there an alternative to the full-leg radiograph for determining knee joint alignment in osteoarthritis? Arthritis Care \& Research 2006; 55(2): 306-13.

24. Moreland JR, Bassett LW, Hanker GJ. Radiographic analysis of axial alignment of the lower extremity. J Bone Joint Surg-Am Vol 1987; 69: 745-9.

25. Ornetti P, Brandt K, Hellio-Le Graverand MP, et al. OARSI-OMERACT definition of relevant radiological progression in hip/knee osteoarthritis. Osteoarthritis and Cartilage 2009; 17(7): 856-63.

26. Cooper C, Adachi JD, Bardin T, et al. How to define responders in osteoarthritis. Current Medical Research and Opinion 2013; 29(6): 719-29.

27. Niu J, Clancy M, Aliabadi P, Vasan R, Felson DT. Metabolic Syndrome, Its Components, and Knee Osteoarthritis: The Framingham Osteoarthritis Study. Arthritis \& Rheumatology 2017; 69(6): 1194203.

28. Wasserstein RL, Lazar NA. The ASA's Statement on p-Values: Context, Process, and Purpose. The American Statistician 2016; 70(2): 129-33.

29. Hawthorne G, Osborne RH, Taylor A, Sansoni J. The SF36 Version 2: critical analyses of population weights, scoring algorithms and population norms. Quality of Life Research 2007; 16(4): 661-73.

30. Hochberg MC, Altman RD, April KT, et al. American college of rheumatology 2012 recommendations for the use of nonpharmacologic and pharmacologic therapies in osteoarthritis of the hand, hip, and knee. Arthritis Care \& Research 2012; 64(4): 465-74.

31. McAlindon TE, Bannuru RR, Sullivan MC, et al. OARSI guidelines for the non-surgical management of knee osteoarthritis. Osteoarthritis and Cartilage 2014; 22(3): 363-88.

32. Bjordal JM, Ljunggren AE, Klovning A, Slørdal L. Non-steroidal anti-inflammatory drugs, including cyclo-oxygenase-2 inhibitors, in osteoarthritic knee pain: meta-analysis of randomised placebo controlled trials. Br Med J 2004; 329(7478): 1317.

33. Day RO, Graham GG. Non-steroidal anti-inflammatory drugs (NSAIDs). BMJ 2013; 346: f3195.

34. Huskisson EC, Berry H, Gishen P, Jubb RW, Whitehead J. Effects of antiinflammatory drugs on the progression of osteoarthritis of the knee. LINK Study Group. Longitudinal Investigation of Nonsteroidal Antiinflammatory Drugs in Knee Osteoarthritis. The Journal of rheumatology 1995; 22(10): 1941-6. 
35. Reijman M, Bierma-Zeinstra SM, Pols HA, Koes BW, Stricker BH, Hazes JM. Is there an association between the use of different types of nonsteroidal antiinflammatory drugs and radiologic progression of osteoarthritis? The Rotterdam Study. Arthritis \& Rheumatism 2005; 52(10): 3137-42.

36. Lapane KL, Yang S, Driban JB, et al. Effects of prescription nonsteroidal antiinflammatory drugs on symptoms and disease progression among patients with knee osteoarthritis. Arthritis \& Rheumatology 2015; 67(3): 724-32.

37. Wluka AE, Ding C, Wang Y, Jones G, Urquhart DM, Cicuttini FM. Aspirin is associated with reduced cartilage loss in knee osteoarthritis: Data from a cohort study. Maturitas 2015; 81(3): 394-7.

38. Maly MR. Abnormal and cumulative loading in knee osteoarthritis. Curr Opin Rheumatol 2008; 20(5): 547-52.

39. Timmins KA, Leech RD, Batt ME, Edwards KL. Running and Knee Osteoarthritis: A Systematic Review and Meta-analysis. The American Journal of Sports Medicine 2017; 45(6): 1447-57.

40. Dean E, Gormsen Hansen R. Prescribing optimal nutrition and physical activity as “First-Line” interventions for best practice management of chronic low-grade inflammation associated with osteoarthritis: evidence synthesis. Arthritis 2012; 2012: 560634.

41. Pietrosimone B, Thomas AC, Saliba SA, Ingersoll CD. Association between quadriceps strength and self-reported physical activity in people with knee osteoarthritis. International Journal of Sports Physical Therapy 2014; 9(3): 320-8.

42. Bennell KL, Hunt MA, Wrigley TV, Lim B-W, Hinman RS. Role of Muscle in the Genesis and Management of Knee Osteoarthritis. Rheum Dis Clin North Am 2008; 34(3): 731-54.

43. Martel-Pelletier J, Roubille C, Abram F, et al. First-line analysis of the effects of treatment on progression of structural changes in knee osteoarthritis over 24 months: data from the osteoarthritis initiative progression cohort. Ann Rheum Dis 2015; 74(3): 547-56.

44. Sawitzke AD, Shi H, Finco MF, et al. The effect of glucosamine and/or chondroitin sulfate on the progression of knee osteoarthritis: a report from the Glucosamine/Chondroitin Arthritis Intervention Trial. Arthritis \& Rheumatism 2008; 58(10): 3183-91.

45. Zhang Y, Niu J, Felson DT, Choi HK, Nevitt M, Neogi T. Methodologic challenges in studying risk factors for progression of knee osteoarthritis. Arthritis Care \& Research 2010; 62(11): 1527-32.

\section{Tables}


Table 1:

Participant characteristics at baseline $(n=498)$.

\begin{tabular}{|c|c|}
\hline Characteristic & mean (sd) \\
\hline Age (years) & $60(8)$ \\
\hline Female, N (\%) & $282(57 \%)$ \\
\hline Mass $(k g)$ & $81(16)$ \\
\hline Height $(m)$ & $1.68(0.95)$ \\
\hline $\mathrm{BMI}\left(\mathrm{kg} / \mathrm{m}^{2}\right)$ & $28.7(5.3)$ \\
\hline Waist circumference $(\mathrm{cm})$ & $95.1(13.7)$ \\
\hline $\begin{array}{l}\text { Females } \\
(\% \text { with circumference }>88 \mathrm{~cm})\end{array}$ & $\begin{array}{l}90.7(13.6) \\
(52 \%)\end{array}$ \\
\hline $\begin{array}{l}\text { Males } \\
(\% \text { with circumference }>102 \mathrm{~cm})\end{array}$ & $\begin{array}{l}101.0(11.5) \\
(40 \%)\end{array}$ \\
\hline Symptom duration (years) & $2.5(1.3)$ \\
\hline Medial Joint space width $(\mathrm{mm})$ & $3.8(1.0)$ \\
\hline \multicolumn{2}{|l|}{ OA severity (K\&L grade), $\mathrm{n}(\%)$} \\
\hline Grade 1 & $273(55 \%)$ \\
\hline Grade 2 & $202(41 \%)$ \\
\hline Grade 3 & $23(5 \%)$ \\
\hline Knee alignment $\left(^{\circ}\right)$ & $181(2.4)$ \\
\hline Knee Pain (WOMAC 0-20) & $6.7(3.6)$ \\
\hline Physical Function (WOMAC 0-68) & $21.8(12.7)$ \\
\hline SF 12 PCS & $41.4(9.6)$ \\
\hline SF 12 MCS & $48.7(6.8)$ \\
\hline Comorbidity score & $3.2(3.0)$ \\
\hline Use of non-steroidal anti-inflammatory drugs, $n(\%)$ & $140(28 \%)$ \\
\hline Aspirin & 49 \\
\hline Meloxicam & 34 \\
\hline Ibuprofen & 23 \\
\hline Diclofenac & 17 \\
\hline
\end{tabular}




\begin{tabular}{|l|l|}
\hline Celecoxib & 13 \\
\hline Naproxen & 8 \\
\hline Indomethacin, Ketoprofen, or Piroxicam & 7 \\
\hline
\end{tabular}

*Note: More than one drug was used by ten participants

Legend: N: Number; BMI: Body Mass Index; OA: Osteoarthritis; K\&L: Kellgren and Lawrence; WOMAC: Western Ontario and McMaster Universities (WOMAC) OA index; SF: Short Form; PCS: Physical Component Score; MCS: Mental Component Score 
Table 2:

Univariate analyses: number (\%) with radiographic OA progression, $\mathrm{p}$ values for association between independent variables and radiographic OA progression (JSN $\geq 0.5 \mathrm{~mm}$ ) using Pearson $\chi^{2}$.

Independent variables

Radiographic OA

Progression

$\geq 0.5 \mathrm{~mm}$ at follow-up: $\mathrm{n}$

(\%)

$\begin{array}{lll}\begin{array}{l}\text { Yes } \\ (n=58)\end{array} & \begin{array}{l}\text { No } \\ (n=440)\end{array} & \begin{array}{l}\text { Unadjusted odds } \\ \text { ratio }\end{array}\end{array}$

value

\section{Clinical factors}

\begin{tabular}{|c|c|c|c|c|}
\hline Sex (Female) & $29(50 \%)$ & $253(58 \%)$ & $0.74(0.43,1.28)$ & 0.28 \\
\hline Aged $>60$ years & $34(59 \%)$ & $238(54 \%)$ & $1.20(0.69,2.10)$ & 0.52 \\
\hline Obesity* & $30(52 \%)$ & $225(51 \%)$ & $1.02(0.59,1.77)$ & 0.93 \\
\hline High blood pressure & $17(29 \%)$ & $146(33 \%)$ & $0.84(0.46,1.52)$ & 0.56 \\
\hline Heberden Nodes & $17(29 \%)$ & $130(30 \%)$ & $0.99(0.54,1.80)$ & 0.97 \\
\hline Manual occupation & $11(19 \%)$ & $63(14 \%)$ & $1.40(0.69,2.85)$ & 0.35 \\
\hline Knee trauma or surgery history & $24(41 \%)$ & $182(41 \%)$ & $1.00(0.57,1.75)$ & 1.00 \\
\hline No glucosamine/chondroitin & $46(79 \%)$ & $323(73 \%)$ & $1.39(0.71,2.71)$ & 0.34 \\
\hline Use of NSAIDs & $21(36 \%)$ & $119(27 \%)$ & $1.53(0.86,2.72)$ & 0.14 \\
\hline Use of statins & $16(28 \%)$ & $115(26 \%)$ & $1.08(0.58,1.99)$ & 0.81 \\
\hline Inadequate physical activity & $50(86 \%)$ & $330(75 \%)$ & $2.08(0.96,4.53)$ & 0.06 \\
\hline 0) High baseline pain (WOMAC pain & $8(14 \%)$ & $104(24 \%)$ & $0.52(0.24,1.13)$ & 0.09 \\
\hline $\begin{aligned} & \text { Poor physical function (WOMAC } \\
= & 33 \text { ) }\end{aligned}$ & $9(16 \%)$ & $100(23 \%)$ & $0.62(0.30,1.32)$ & 0.21 \\
\hline \multicolumn{5}{|l|}{ ructural disease severity } \\
\hline Disease severity ( $K \& L$ grade $\geq 2$ ) & $39(67 \%)$ & $186(42 \%)$ & $2.80(1.57,5.01)$ & $<0.001$ \\
\hline $\begin{array}{l}\text { Minimal joint space width } \\
3.13 \mathrm{~mm})\end{array}$ & $27(47 \%)$ & $89(20 \%)$ & $3.44(1.95,6.05)$ & $<0.001$ \\
\hline Varus alignment $\left(\leq 178^{\circ}\right)$ & 19 (33\%) & $54(12 \%)$ & $3.45(1.86,6.39)$ & $<0.001$ \\
\hline
\end{tabular}

Legend:*: Obesity defined as Body Mass Index $\geq 30 \mathrm{~kg} / \mathrm{m}^{2}$ and $/$ or high waist circumference $(>102 \mathrm{~cm}$ for men, $>88 \mathrm{~cm}$ for women); NSAIDs: Non-steroidal anti-inflammatory drugs; WOMAC: Western Ontario and McMaster Universities (WOMAC) OA index; PF: Physical Function subscale; K\&L: Kellgren and Lawrence 
Table 3:

Unadjusted and adjusted (multivariable) associations between independent variables (clinical and fixed variables) and radiographic OA progression (JSN $\geq 0.5 \mathrm{~mm}$ )

\begin{tabular}{|c|c|c|c|c|c|}
\hline Independent variables & $\begin{array}{l}\text { Exposed with } \\
\text { progression }\end{array}$ & $\begin{array}{l}\text { Non-exposed } \\
\text { with progression }\end{array}$ & $\begin{array}{l}\text { Unadjusted } \\
\text { odds ratio } \\
(95 \% \mathrm{Cl})\end{array}$ & $\begin{array}{l}\text { Adjusted } \\
\text { odds ratio } \\
(95 \% \mathrm{Cl})\end{array}$ & $\begin{array}{l}\mathrm{p}- \\
\text { value }\end{array}$ \\
\hline \multicolumn{6}{|c|}{ Radiographic OA progression $\left(R^{2}=16 \%\right)$} \\
\hline \multicolumn{6}{|l|}{ Clinical factors } \\
\hline Use of NSAIDs & $15.0 \%$ & $10.3 \%$ & $\begin{array}{l}1.53(0.86 \\
2.72)\end{array}$ & $\begin{array}{l}2.05(1.10 \\
3.84)\end{array}$ & 0.025 \\
\hline $\begin{array}{l}\text { Inadequate physical } \\
\text { activity }\end{array}$ & $13.2 \%$ & $6.8 \%$ & $\begin{array}{l}2.08(0.96 \\
4.53)\end{array}$ & $\begin{array}{l}2.07(0.92, \\
4.68)\end{array}$ & 0.080 \\
\hline \multicolumn{6}{|l|}{ Fixed variables } \\
\hline $\begin{array}{l}\text { Minimal joint space } \\
\text { width }(<3.13 \mathrm{~mm})\end{array}$ & $23.3 \%$ & $8.1 \%$ & $\begin{array}{l}3.44(1.95 \\
6.05)\end{array}$ & $\begin{array}{l}2.53(1.31 \\
4.88)\end{array}$ & 0.006 \\
\hline Varus alignment $\left(\leq 178^{\circ}\right)$ & $26.0 \%$ & $9.3 \%$ & $\begin{array}{l}3.45(1.86 \\
6.39)\end{array}$ & $\begin{array}{l}2.23(1.09 \\
4.57)\end{array}$ & 0.028 \\
\hline $\begin{array}{l}\text { Disease severity (K\&L } \\
\text { grade } \geq 2 \text { ) }\end{array}$ & $17.3 \%$ & $7.0 \%$ & $\begin{array}{l}2.80(1.57 \\
5.01)\end{array}$ & $\begin{array}{l}1.88(0.98 \\
3.58)\end{array}$ & 0.056 \\
\hline Age (>60 years) & $12.5 \%$ & $10.6 \%$ & $\begin{array}{l}1.20 \\
(0.69,2.10)\end{array}$ & $\begin{array}{l}1.02(0.56 \\
1.87)\end{array}$ & 0.939 \\
\hline Sex (Female) & $10.3 \%$ & $13.4 \%$ & $\begin{array}{l}0.74(0.43 \\
1.28)\end{array}$ & $\begin{array}{l}0.88(0.48 \\
1.60)\end{array}$ & 0.666 \\
\hline Obesity* & $11.8 \%$ & $11.5 \%$ & $\begin{array}{l}1.02(0.59 \\
1.77)\end{array}$ & $\begin{array}{l}1.17(0.64 \\
2.14)\end{array}$ & 0.603 \\
\hline High blood pressure & $10.4 \%$ & $12.2 \%$ & $\begin{array}{l}0.84(0.46 \\
1.52)\end{array}$ & $\begin{array}{l}0.65(0.34 \\
1.25)\end{array}$ & 0.198 \\
\hline $\begin{array}{l}\text { High baseline pain } \\
(\text { WOMAC pain >10) }\end{array}$ & $7.1 \%$ & $13.0 \%$ & $\begin{array}{l}0.52(0.24 \\
1.13)\end{array}$ & $\begin{array}{l}0.52(0.23 \\
1.18)\end{array}$ & 0.118 \\
\hline $\begin{array}{l}\text { No } \\
\text { glucosamine/chondroitin } \\
\text { combination }\end{array}$ & $12.5 \%$ & $9.3 \%$ & $\begin{array}{l}1.39(0.71 \\
2.71)\end{array}$ & $\begin{array}{l}1.26(0.62 \\
2.56)\end{array}$ & 0.521 \\
\hline
\end{tabular}

Legend: *: Obesity defined as Body Mass Index $\geq 30 \mathrm{~kg} / \mathrm{m} 2$ and/or high waist circumference $(>102 \mathrm{~cm}$ for men, $>88 \mathrm{~cm}$ for women); NSAIDs: Non-steroidal anti-inflammatory drugs; K\&L:Kellgren and Lawrence; WOMAC: Western Ontario and McMaster Universities (WOMAC) OA index

\section{Figures}




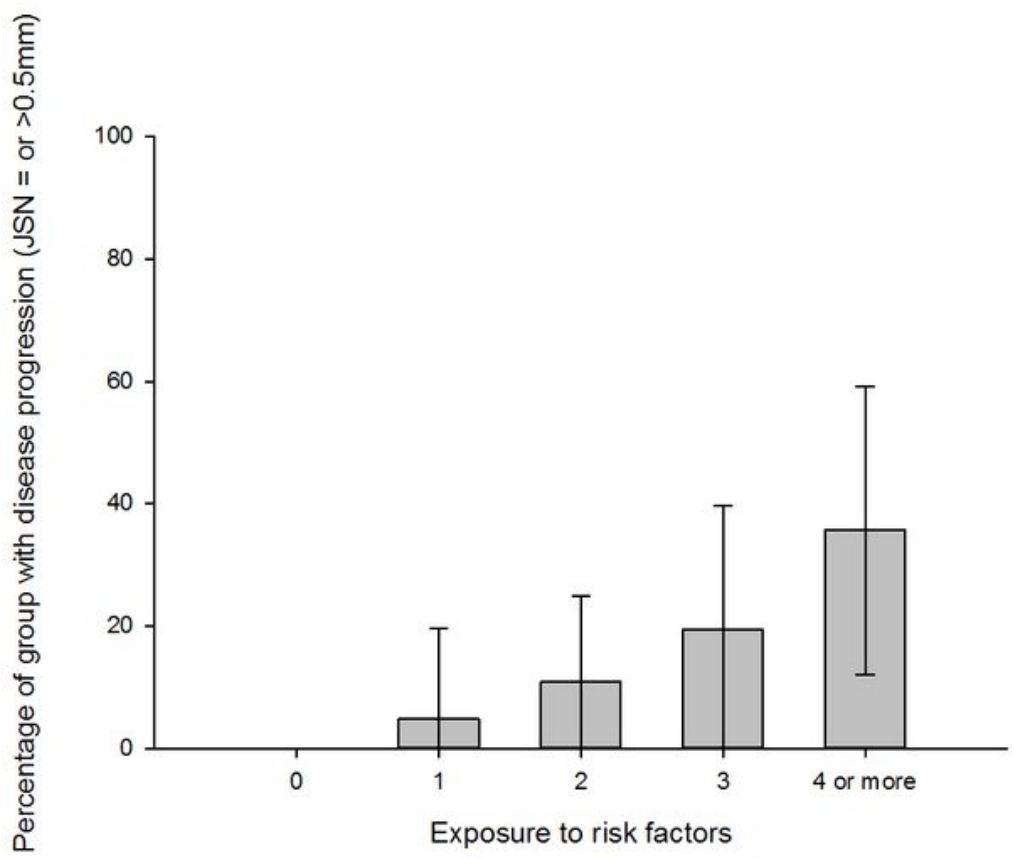

Figure 1

Percentage ( $95 \%$ confidence interval) of participants with radiographic OA progression (JSN $\geq 0.5 \mathrm{~mm}$ ) based on the number of positive risk factors

\section{Supplementary Files}


This is a list of supplementary files associated with this preprint. Click to download.

- Appendix1LEGS.docx 